\section{Metallurgical quality evaluation of the wind turbine main shaft 42CrMo4 steel: microscopic and Mössbauer studies}

Zbigniew Siemiątkowski, Małgorzata Gzik-Szumiata, Tadeusz Szumiata, Mirosław Rucki, Robert Martynowski

\begin{abstract}
In this paper, the results of the complex examination of the 42CrMo4 steel samples are presented. The samples were taken from the metallurgical forging prepared for the production of the wind turbine main shaft. The samples underwent Mössbauer spectroscopic analysis, as well as the measurement of its mechanical characteristics such as hardness and strength are analysed. Conversion electron Mössbauer spectrometry confirmed phase purity and isotropy of the investigated 42CrMo4 steel. The method provided accurate results, proving Mössbauer spectrometry to be an effective tool for the wind turbine main shaft analysis.
\end{abstract}

Keywords: metallurgical forging • wind turbine • Mössbauer spectrometry

\section{Z. Siemiątkowski, M. Rucki}

Institute of Machinery Engineering,

University of Technology and Humanities in Radom,

54 Krasickiego Str., 26-600 Radom, Poland

M. Gzik-Szumiata, T. Szumiata ${ }^{\bowtie}$

Department of Physics,

University of Technology and Humanities in Radom,

54 Krasickiego Str., 26-600 Radom, Poland,

E-mail: t.szumiata@uthrad.pl

R. Martynowski

CELSA Huta Ostrowiec Sp. z o.o.,

Forge Division,

2 Samsonowicza Str., 27-400 Ostrowiec Świętokrzyski, Poland

Received: 7 October 2016

Accepted: 17 November 2016

\section{Introduction}

The need of the renewable energy sources leads to the wide application of the wind turbines. Wind power has seen the widest and most successful deployment over the past two decades, from $3 \mathrm{GW}$ to above $280 \mathrm{GW}$ of global cumulative capacity at the end of 2012. Already in 2011 four European countries (Denmark, Portugal, Ireland, and Spain) obtained more than $10 \%$ of their electricity from wind [1]. The high cost of the wind turbine design and the reparation expenses (major replacements and overhauls over the life of the wind turbine [2]) indicates the need of thorough investigations on the materials [3]. Especially, the main shaft, which is the object of the complex dynamical loads [4], must undergo inspection in order to control the percentage of its initial chemical components, purity, and structural defects, including the structure after the thermochemical treatment and the mechanical machining, as well as the mechanical properties and durability to avoid the cracks, especially those caused by the fatigue [5]. White etching area formation under rolling/sliding contact fatigue causes microstructural changes and cracks that develop in the amorphous-like structure $[6,7]$. The contact geometry causes the fretting wear, contact stresses, and a multiaxial fatigue damage with cumulative damage effects [8]. Moreover, the weight reduction must be considered along with the required mechanical properties [9].

In this paper, the results of chemical and mechanical analyses of the wind turbine main shaft during production are described. The novelty of the presented work is the application of the Mössbauer spectrometry to the atomic structure studies of wind 


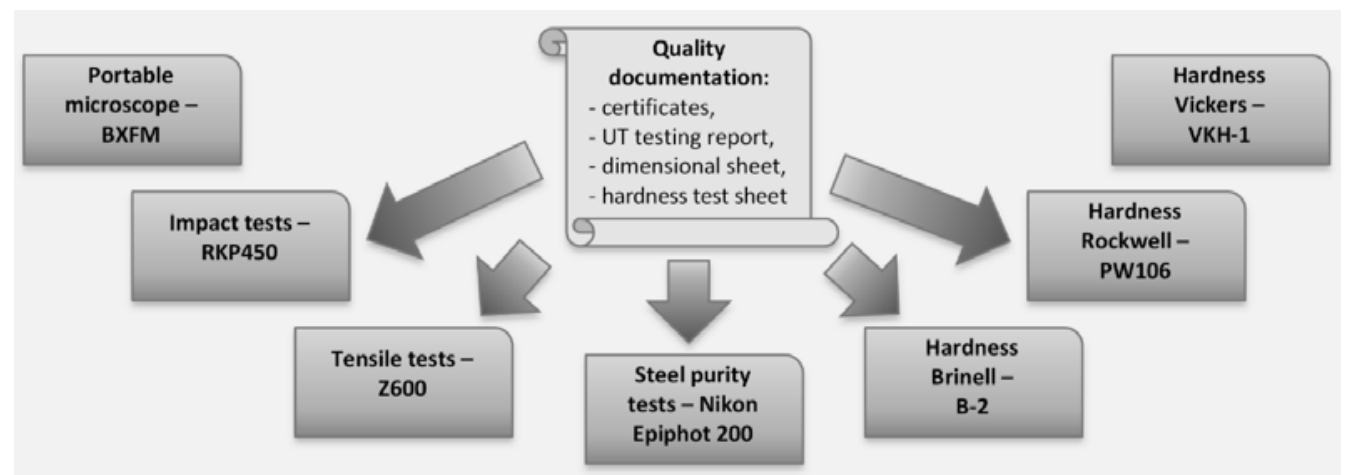

Fig. 1. Typical material characteristics inspection scheme of the wind turbine main shaft made out of $42 \mathrm{CrMo} 4$ steel (the Vickers and Rockwell hardness checks are optional).

turbine shaft. This technique (complementary to optical microscopy and spark spectrometry as well as X-ray diffraction (XRD)) enables the qualitative and quantitative phase analysis of the materials [10-18]. Mössbauer spectrometry based on ${ }^{57} \mathrm{Fe}$ isotope is very effective tool for the material quality investigations of various types of steel, e.g. high-carbon tool steel [10], cold drawn eutectoid steel [11], AISI 1137 type steel [12], nitrided cast steels [13], plasma-nitrided carbon steel [14], as well as corrosion products on steel [15], or the structure of friction products and the surface of tribological system elements [16]. The method even proved to be a useful tool for the study of the atomic short-range order in alloys [17] and interactions of impurity atoms dissolved in iron [18].

One of the basic materials for the wind main shaft production is the 42CrMo4 steel [4]. The main goal of the investigation was to identify all iron-bearing phases in the samples of steel cut from the metallurgical forging.

\section{Experimental}

In order to assess both metallurgical and mechanical characteristics of the $42 \mathrm{CrMo} 4$ steel (1.7225), the samples were taken from the forging during the production of the wind turbine main shaft. The forging mass was 17 tons, and two kinds of samples were taken: from its head part $(\mathrm{H})$ and its foot part $(\mathrm{F})$. The head part samples were taken in axial direction (one sample for the strength test and three for the impact tests). The additional sample was taken to examine the purity of the steel and to perform the blue fracture test. The foot part samples were taken for the strength tests (one in axial direction and one in perpendicular direction) and the impact tests (three in axial direction and three in perpendicular direction); one sample was taken to examine the purity of the steel and one sample to perform the blue fracture test.

The inspected shafts underwent the typical heat treatment (normalization) in order to gain smaller grains as well as the hardening and tempering. For the $42 \mathrm{CrMo} 4$ steel, the critical diameter of the detail that allows full depth heat treatment $\left(D_{50}\right)$ is $90 \mathrm{~mm}$ for the water cooling and $65 \mathrm{~mm}$ for the oil cooling, because this steel has low hardenability. Because the diameter of the forging was much larger than $D_{50}$, the shaft was treated only on the certain depth. The following are heat treatment parameters:

- normalization at the temperature of $870^{\circ} \mathrm{C}$, heating time is $16 \mathrm{~h}$, air cooling,

- quench hardening at the temperature of $860^{\circ} \mathrm{C}$, heating time is $16^{1 / 2} \mathrm{~h}$, water cooling,

- tempering at the temperature of $680^{\circ} \mathrm{C}$, heating time is $24 \mathrm{~h}$, air cooling.

The regular analysis of chemical composition of the forging was made according to the standard EN 10083-3:2006 with the optical emission spectroscopy device ARL 3460.

The typical complex inspection of the material characteristics consisted of the tests shown in Fig. 1. Initial inspection of the surface was performed with the BXFM portable microscope, and more detailed examination of the surface microstructure was made with the metallographic microscope NEOPHOT-2 Carl Zeiss Jena. The purity of the steel was examined with a method according to the ISO 4967:1998 standard using Nikon Epiphot 200 Inverted Metallographic Microscope.

In the described investigations, however, the Vickers and Rockwell hardness values (usually assessed with the devices PW106 and VKH-1, respectively) were not chosen to be measured. The tensile test was made according to the PN-EN ISO 6892-1:2010 standard at a temperature of $23^{\circ} \mathrm{C}$ with the testing machine ZWICK/ROELL Z600 type. The Brinell hardness was measured for the head samples $\mathrm{H}$ (in longitudinal $(\mathrm{L})$ and radial $(\mathrm{R})$ directions) according to the PN EN ISO 6506-1:2008 standard with the device B-2. The impact test was performed with the Charpy hammer RKP450 type made by ZWICK/ROELL according to the PN EN ISO 148-1:2010 standard. The impact velocity was $5.4 \mathrm{~m} / \mathrm{s}$, and the temperature was kept at $-20^{\circ} \mathrm{C}$.

From the sample, the additional analysis of the composition was made in order to obtain and document the complete knowledge on the produced shaft. Structural order and phase composition of steel samples were investigated by means of ${ }^{57} \mathrm{Fe}$-based conversion electron Mössbauer spectrometry (CEMS) at room temperature. A gas flow type conversion electron detector (RiKon-Wissel), supplied with $\mathrm{He}+4 \% \mathrm{CH}_{4}$ mixture, was operating in $2 \pi$ backscattering geometry. The resonant conversion 7.3 and $5.6 \mathrm{keV}$ electrons were counted with 
multichannel analyzer synchronized with vibrator driving ${ }^{57} \mathrm{Co}(\mathrm{Rh})$ source in the constant acceleration mode. The fitting procedure of the spectra was performed with PolMoss package based on MS Excel Solver extension. This software was successfully applied in case of high-magnetostrictive $\mathrm{Fe}-\mathrm{Ga}$ thin films [19]. Each fitted subspectrum was approximated by the Gaussian distributions of hyperfine parameters (in both doublets and Zeeman sextets) convoluted with Lorentzian base lines (Voigt-type profile). Two samples for CEMS measurements were prepared in the form of 2-mm-thick disc and of $15 \mathrm{~mm}$ in diameter (dimensions optimal for fitting inside the CEMS detector). The first sample (R) was cut as transverse section of metallurgical forging from its central part. The second sample (L) was cut longitudinally to the forging axis.

\section{Results and discussion}

Figure 2 presents the pictures obtained from the NEOPHOT-2 microscope for the head part samples $(\mathrm{H})$. The samples were cut in cubicoid shape, and then the structure underwent examination in three directions: longitudinal (L), radial (R), and tangential $(\mathrm{T})$ to the surface directions. The samples were etched with nital. The structure of the tempered martensite is clearly distinguished, and in the deep layers, it may contain bainite, that is, sorbite. The post-martensite acicular order is clearly seen, revealing the spheroidization processes of the large dispersion carbides. The observed structure is correct and meets the specification requirement.

The chemical composition compared to the standard is presented in Table 1, in which two sets of the results are presented: the regular and additional ones. It is so because the company CELSA Huta Ostrowiec, where the investigations were being performed, kept higher standards in order to guarantee the customer satisfaction. Thus, the analysis of chemical composition of the main shaft was performed additionally on the sample, to reveal more components, even those not specified in the standard. Slight differences in the results between the regular and additional ones are the random deviations caused by the sampling process and the measurement uncertainty. Noteworthy are the low values of the $\mathrm{Cu}, \mathrm{V}$, and $\mathrm{Al}$, as well as $\mathrm{H}_{2}$, that prove high quality of the produced material.

a) Longitudinal direction (L)

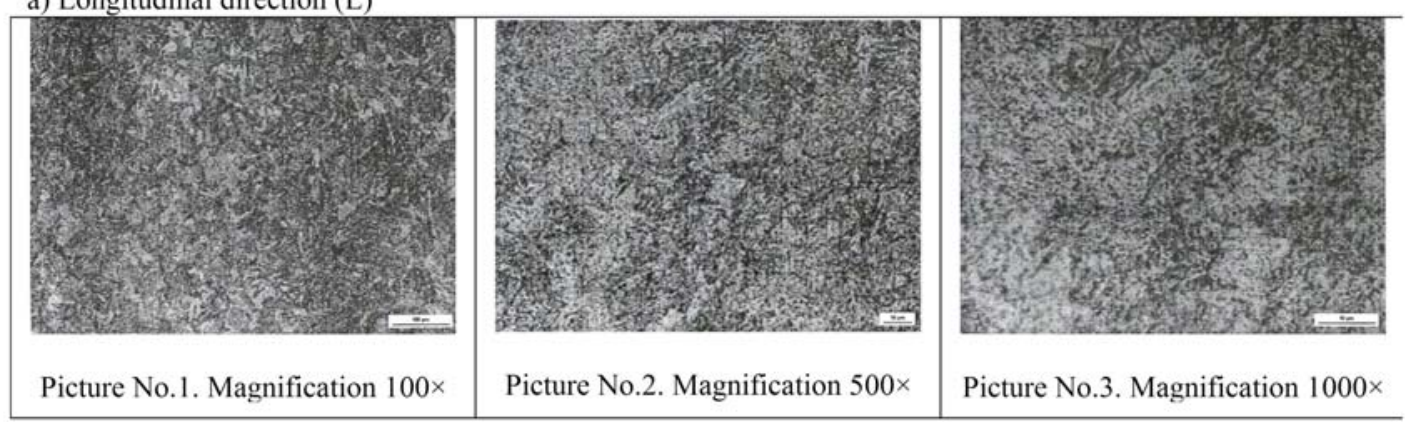

b) Radial direction (R)

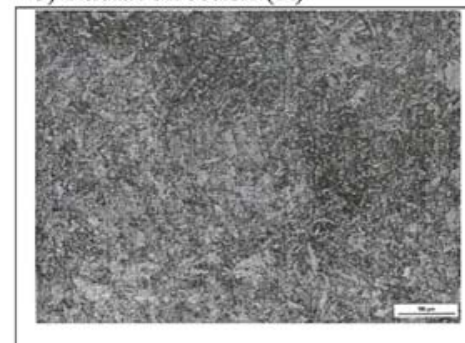

Picture No.4. Magnification $100 \times$

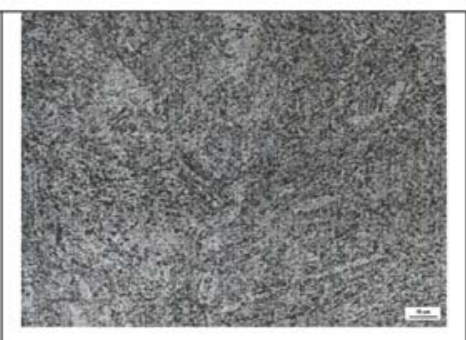

Picture No.5. Magnification 500×

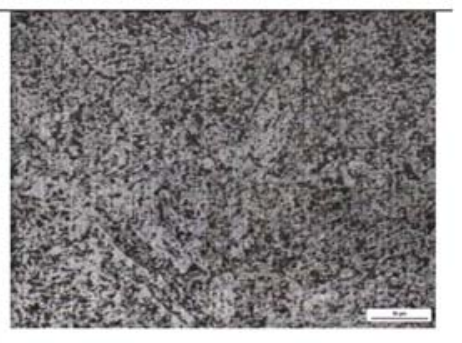

Picture No.6. Magnification 1000×

c) Tangential direction (T)

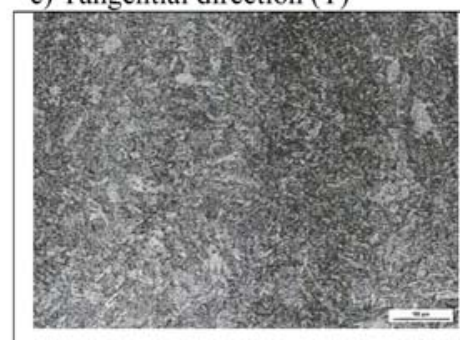

Picture No.7. Magnification $100 \times$

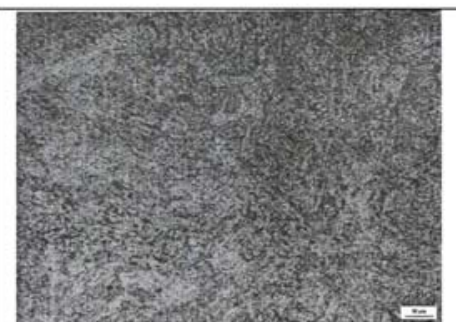

Picture No.8. Magnification 500×

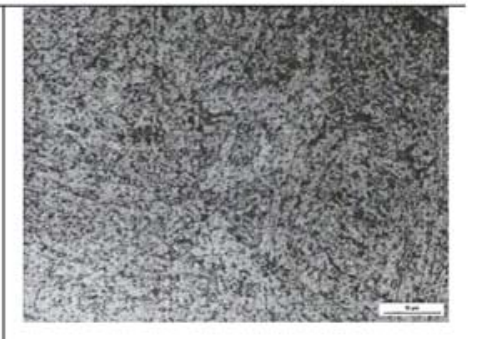

Picture No.9. Magnification 1000×

Fig. 2. Head part samples of $42 \mathrm{CrMo} 4$ steel etched with the nital in (a) longitudinal, (b) radial and (c) tangential directions. 
Table 1. Chemical composition in percentage of 42CrMo4 steel according to the EN 10083-3:2006 standard

\begin{tabular}{|c|c|c|c|c|c|c|c|c|c|c|c|c|}
\hline & $\mathrm{C}$ & $\mathrm{Mn}$ & $\mathrm{Si}$ & $\mathrm{P}$ & $\mathrm{S}$ & $\mathrm{Cr}$ & $\mathrm{Ni}$ & Mo & $\mathrm{Cu}$ & V & $\mathrm{Al}$ & $\mathrm{H}_{2}[\mathrm{ppm}]$ \\
\hline Min & 0.38 & 0.50 & - & - & - & 0.90 & 0.50 & 0.15 & - & - & - & - \\
\hline Max & 0.45 & 0.80 & 0.40 & 0.035 & 0.035 & 1.20 & 0.70 & 0.30 & - & - & - & - \\
\hline \multicolumn{13}{|c|}{ Test results [\%] } \\
\hline $\begin{array}{l}\text { Regular } \\
\text { (heat analysis) }\end{array}$ & 0.39 & 0.73 & 0.19 & 0.006 & 0.002 & 1.16 & 0.60 & 0.26 & 0.06 & 0.054 & 0.0077 & 0.800 \\
\hline $\begin{array}{l}\text { Additional } \\
\text { (sample test) }\end{array}$ & \multicolumn{12}{|c|}{ 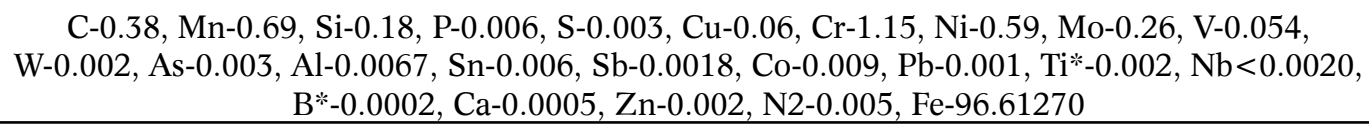 } \\
\hline
\end{tabular}

* Overall content of the element.

Table 2. Impact test results according to the PN EN ISO 148-1:2010 standard

\begin{tabular}{|c|c|c|c|}
\hline \multirow{2}{*}{ No. } & \multirow{2}{*}{$\begin{array}{l}\text { Specimen } \\
\text { ID }\end{array}$} & \multicolumn{2}{|c|}{ Absorbed energy [J] } \\
\hline & & & Average \\
\hline$\overline{1}$ & & 60.5 & \\
\hline 2 & $\mathrm{~L}$ & 46.8 & 54 \\
\hline 3 & & 54.5 & \\
\hline 4 & & 52.0 & \\
\hline 5 & $\mathrm{R}$ & 53.7 & 46 \\
\hline 6 & & 31.1 & \\
\hline
\end{tabular}

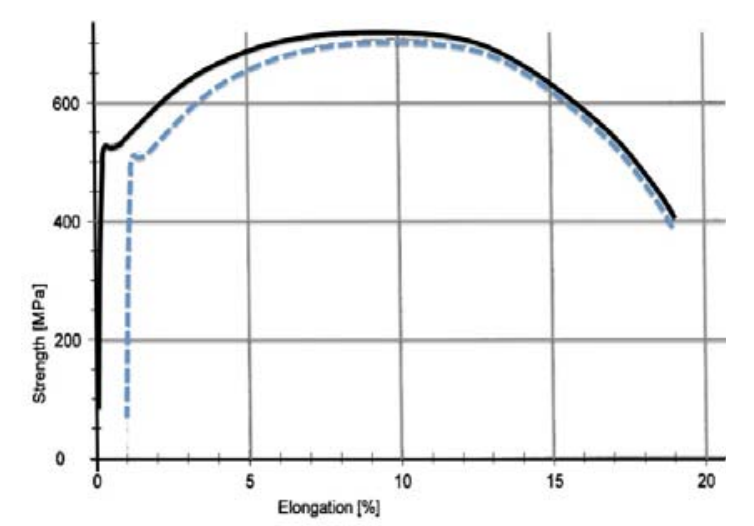

Fig. 3. Static tensile test graph.
The Brinell hardness of the examined samples was as follows: $\mathrm{L}=208,208 \mathrm{HBW} ; \mathrm{R}=208,205$ HBW. The results of the impact test performed are presented in Table 2, while Fig. 3 and Table 3 present the tensile test results.

CEMS spectra collected at room temperature for two samples of metallurgical forging are presented in Fig. 4 and fitting parameters of theoretical spectra are listed in Table 4.

The dominating $\alpha$ component (more than $76 \%$ ) is represented by narrow distribution of Zeeman sextets of mean hyperfine field value $B_{0}=33.2 \mathrm{~T}$ - slightly higher than that for pure bcc $\alpha$-Fe (or low-carbon ferrite), but lower than that for supersaturated bct $\mathrm{Fe}(\mathrm{C})$ alloy (martensite) [16]. Similar hyperfine field value was reported in [11] for almost eutectoid steel and attributed to such iron atoms in ferrite with the most of nearest neighbours as iron. The half-width (variance) $\Delta(B)$ of hyperfine field distribution was of the order of $0.5-0.6 \mathrm{~T}$. The isomer shift $\left(\mathrm{IS}_{0}\right)$ and quadrupole splitting $\left(\mathrm{QS}_{0}\right)$ mean values of the $\alpha$ component are very close to zero. According to [11], the second considerable component in the spectra (denoted as $B$ and characterized by the hyperfine field distribution of $30.8 \mathrm{~T}$ mean value) can be assigned to the $\alpha$-matrix of ferrite distorted by alloying impurity atoms (mostly Mn, Ni, Si, Cr, Mo). The half-width of this hyperfine distribution is relatively large (1.1-1.3 T).

Table 3. Strength test of the $42 \mathrm{CrMo} 4$ steel at a temperature of $23^{\circ} \mathrm{C}$ according to the PN-EN ISO 6892-1:2010 standard

\begin{tabular}{lcccccccccccc}
\hline No. & $\begin{array}{c}D_{0} \\
{[\mathrm{~mm}]}\end{array}$ & $\begin{array}{c}S_{0} \\
{\left[\mathrm{~mm}^{2}\right]}\end{array}$ & $\begin{array}{c}L_{0} \\
{[\mathrm{~mm}]}\end{array}$ & $\begin{array}{c}E \\
{[\mathrm{GPa}]}\end{array}$ & $\begin{array}{c}d L \\
{[\mathrm{~mm}]}\end{array}$ & $\begin{array}{c}A_{5} \\
{[\%]}\end{array}$ & $\begin{array}{c}d_{u} \\
{[\mathrm{~mm}]}\end{array}$ & $\begin{array}{c}F_{0.2} \\
{[\mathrm{~N}]}\end{array}$ & $\begin{array}{c}R p_{0.2} \\
{[\mathrm{MPa}]}\end{array}$ & $\begin{array}{c}F m \\
{[\mathrm{~N}]}\end{array}$ & $\begin{array}{c}R m \\
{[\mathrm{MPa}]}\end{array}$ & $\begin{array}{c}Z \\
{[\%]}\end{array}$ \\
\hline $1 . \mathrm{L}$ & \multirow{2}{*}{14} & \multirow{2}{*}{153.94} & \multirow{2}{*}{70} & 205.8 & 15.8 & 22.6 & 7.7 & 81,587 & 530 & 109,961 & 714 & 70 \\
$2 . \mathrm{R}$ & & & & & & & & & &
\end{tabular}
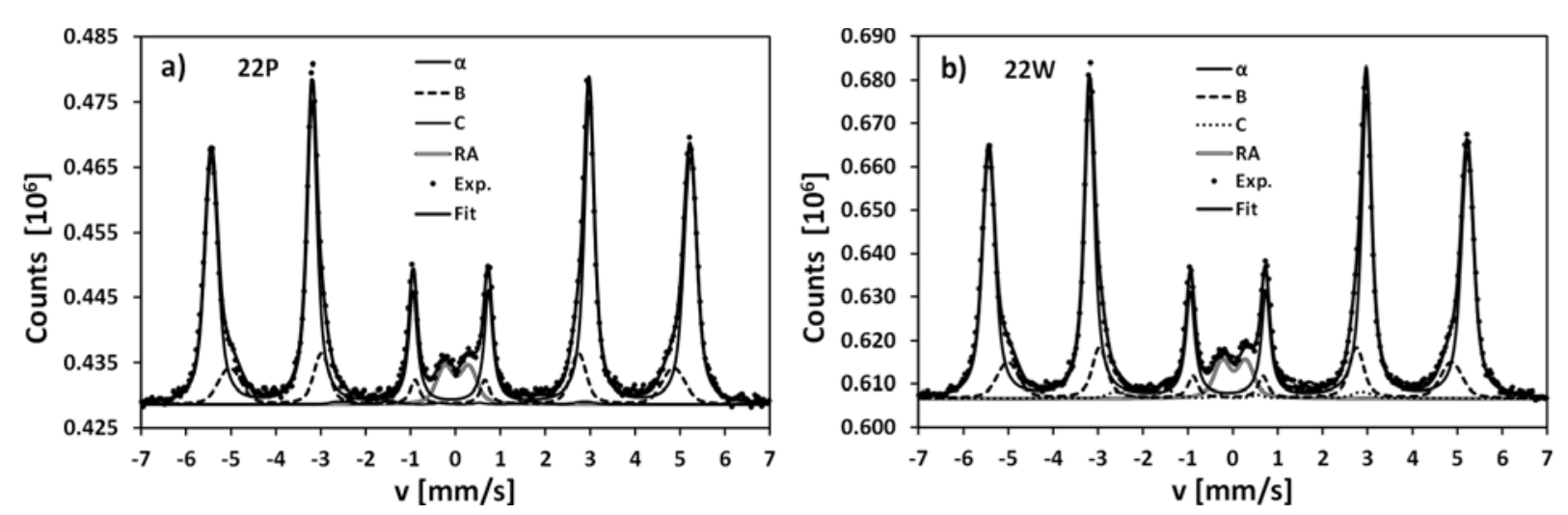

Fig. 4. Room-temperature CEMS spectra for perpendicularly (a) and longitudinally (b) cut samples of $42 \mathrm{CrMo} 4$ steel from metallurgical forging. 
Table 4. Hyperfine parameters obtained from fitting procedure of CEMS spectra for perpendicularly (R) and longitudinally (L) cut samples of 42CrMo4 steel from metallurgical forging. Symbols and their meaning: $P$ - percentage contribution, $\mathrm{IS}_{0}-$ mean value of isomer shift, $\mathrm{QS}_{0}-$ mean value of quadrupole splitting, $\Delta(\mathrm{QS})$ - variance of quadrupole splitting distribution, $B_{0}$ - mean value of hyperfine field distribution, $\Delta(B)$ - variance of hyperfine field distribution, $\theta$ - angle between incident X-ray direction and the direction of hyperfine field

\begin{tabular}{ccccccccc}
\hline Sample & Component & $\begin{array}{c}P \\
{[\%]}\end{array}$ & $\begin{array}{c}\mathrm{IS}_{0} \\
{[\mathrm{~mm} / \mathrm{s}]}\end{array}$ & $\begin{array}{c}\mathrm{QS}_{0} \\
{[\mathrm{~mm} / \mathrm{s}]}\end{array}$ & $\begin{array}{c}\Delta(\mathrm{QS}) \\
{[\mathrm{mm} / \mathrm{s}]}\end{array}$ & $\begin{array}{c}B_{0} \\
{[\mathrm{~T}]}\end{array}$ & $\begin{array}{c}\Delta(B) \\
{[\mathrm{T}]}\end{array}$ & $\begin{array}{c}\theta \\
{[\mathrm{deg}]}\end{array}$ \\
\hline \multirow{3}{*}{$\mathrm{R}$} & $\alpha$ & 76.3 & 0.004 & 0.002 & 0 & 33.21 & 0.58 \\
& $\mathrm{~B}$ & 16.9 & 0.010 & 0.037 & 0 & 30.77 & 1.27 & 68.9 \\
& $\mathrm{C}$ & 1.2 & 0.240 & 0.037 & 0 & 17.00 & 1.00 & - \\
$\mathrm{L}$ & $\mathrm{RA}$ & 5.6 & 0.141 & 0.525 & 0.266 & 0 & 0 & \\
& $\alpha$ & 76.5 & 0.004 & -0.002 & 0 & 33.20 & 0.52 & \\
& $\mathrm{~B}$ & 16.3 & 0.015 & 0.023 & 0 & 30.81 & 1.13 & 69.8 \\
& $\mathrm{C}$ & 1.2 & 0.240 & 0.037 & 0 & 17.00 & 1.00 & - \\
\hline
\end{tabular}

The subspectrum $B$ is characterized by non-zero but relatively low values of both isomer shift and quadrupole spitting. The contribution of this component exceeds $16 \%$. Some fitting quality improvement has been achieved by introducing a broad component $\mathrm{C}$ of fixed hyperfine parameter values obtained as averages over components corresponding to Hägg carbide $\chi-\mathrm{Fe}_{2.5} \mathrm{C}$ ([20]). Nevertheless, the content of this phase is almost negligible $(1.2 \%)$. The last component, designated as RA and represented by broad doublet, can by identified as retained austenite (fcc $\gamma$-Fe) [21]. The mean value of quadrupole splitting is of the order of $0.53 \mathrm{~mm} / \mathrm{s}$. The half-width of quadrupole splitting distribution $\Delta(\mathrm{QS})$ is very significant - around half of $\mathrm{QS}_{0}$. The contribution of retained austenite does not exceed $6 \%$. In the CEMS spectra of the investigated samples, no traces of iron oxides were found (neither ferromagnetic nor paramagnetic). The ratio of the amplitude of the central lines to the inner lines in all fitted Zeeman sextets took value close to 3 , which corresponds to the angle between incident X-ray direction and the direction of hyperfine field (and spin) of the value about $70^{\circ}$. It is a sign of magnetic shape anisotropy favouring more in-plane spin orientation in the case of flat disk-like samples.

CEMS outcomes presented above point to almost pure ferritic phase only with traces of carbides and retained austenite. Referring to the hyperfine magnetic field value of dominating component $\alpha$, this phase can be classified as carbon-saturated ferrite, but still not martensite. Very good statistics of CEMS spectra enables to analyse the very subtle differences in hyperfine parameter values of subspectra for two investigated samples. In both cases, the sample $\mathrm{R}$ is cut radially and the sample $\mathrm{L}$ cut longitudinally along the forging axis, the hyperfine magnetic field values are practically identical (see Table 4). In the first sample, the contribution of ferrite part rich in alloying elements (B component) is higher by about $0.5 \%$, whereas in the second sample, the contribution of non-ferritic phases is higher by less than $0.5 \%$. These facts confirm the high isotropy of all elements and phase content distribution in forging after thermal processing.

Thus, the application of conversion electron Mössbauer spectrometry enabled to determine the phase purity of the $42 \mathrm{CrMo} 4$ steel forging with carbon saturated ferrite as dominating constituent. Only traces of iron carbides and retained austenite were found. The investigated forging revealed high isotropy of elemental and phase distribution. Along with the chemical component analysis and the mechanical properties, it indicates very high quality of the forging for the wind turbine main shaft production.

\section{Conclusions}

The examined material of the 42CrMo4 steel forging performed all the characteristics required of the high-quality wind turbine main shaft. The samples successfully passed all the typical mechanical tests as well as the check of the chemical composition. However, the company CELSA Huta Ostrowiec in the effort to eliminate any chance of the mechanical failure, especially the ones caused by the hidden material discontinuity, decided to make additional thorough analysis of the shaft with the Mössbauer spectrometry method. This way, the investigated forging revealed high isotropy of elemental and phase distribution and phase purity of the $42 \mathrm{CrMo} 4$ steel forging with carbon saturated ferrite as dominating constituent. These characteristics suggest the lack of material defects inside all the forging, which ensure high safety of the further shaft exploitation.

The presented results and analysis confirmed that the Mössbauer spectrometry is a useful and an effective tool for the material studies of samples cut from metallurgical forging of wind turbine shaft. This technique is especially successful when the investigated grade of steel is almost monophase one. In this case, the more common XRD method is usually not sufficiently sensitive in detecting the trace phases of several percent contributions. Moreover, even contributions of dominating phases are estimated more precisely with Mössbauer spectrometry than with XRD - especially when corresponding lattice constants of their crystalline structures are very similar. Thus in many papers devoted to the investigation of steel, the XRD analysis is entirely omitted [11, 12, 21].

On the other hand, the obvious disadvantage of ${ }^{57} \mathrm{Fe}$ Mössbauer spectrometry is that it takes a long 
time for measurements (typically several days per one sample) and is suitable only in the case of the iron-bearing materials. Moreover, the reliable estimation of crystalline phase contributions is possible only when all phases are characterized by similar values of the Debye-Waller factors [12].

The study led also to the interesting area for the application of Mössbauer spectrometry (both transmission technique and CEMS) to a phase analysis of the friction surfaces and wear products [16]. In the future research, the idea of Mössbauer spectrometry could be extended to the case of the large-sized friction nodes tribological studies on the wind turbine shafts in real devices. Such perspective would help to understand more deeply the mechanisms of wear in correlation with elemental and phase content of steel.

\section{References}

1. Arántegui, R. L., Corsatea, T., \& Suomalainen, K. (2012). 2012 JRC wind status report. Petten: Joint Research Centre. (Report EUR 25647 EN).

2. Fingersh, L., Hand, M., \& Laxson, A. (2006). Wind turbine design cost and scaling model. Golden: National Renewable Energy Laboratory. (Technical Report NREL/TP-500-40566).

3. Greco, A., Sheng, S., Keller, J., \& Erdemir, A. (2013). Material wear and fatigue in wind turbine systems. Wear, 302, 1583-1591. DOI: 10.1016/j. wear.2013.01.060.

4. Herrmann, J., Rauert, T., Dalhoff, P., \& Sander, M. (2016). Fatigue and fracture mechanical behaviour of a wind turbine rotor shaft made of cast iron and forged steel. Procedia Structural Integrity, 2, 2951-2958. DOI: 10.1016/j.prostr.2016.06.369.

5. Zhang, Z., Yin, Z., Han, T., \& Tan, A. C. C. (2013). Fracture analysis of wind turbine main shaft. Eng. Fail. Anal., 34, 129-139. DOI: 10.1016/j.engfailanal.2013.07.014.

6. Harada, H., Mikami, T., Shibata, M., Sokai, D., Yamamoto, A., \& Tsubakino, H. (2005). Microstructural changes and crack initiation with white etching area formation under rolling/sliding contact in bearing steel. ISIJ Int., 45(12), 1897-1902. DOI: 10.2355/ isijinternational.45.1897.

7. Carroll, R. I., \& Beynon, J. H. (2007). Rolling contact fatigue of white etching layer: part 1. Crack morphology. Wear, 262, 1253-1266. DOI: 10.1016/j. wear.2007.01.003.

8. Madge, J. J., Leen, S. B., McColl, I. R., \& Shipway, P. H. (2007). Contact-evolution based prediction of fretting fatigue life: Effect of slip amplitude. Wear, 262, 1159-1170. DOI: 10.1016/j.wear.2006.11.004.

9. Huth, R. E. (2008, February). Vertical wind turbine shaft design trade study. Retrieved September,
23, 2016, from http://www3.nd.edu/ me463c18/ Trade\%20Studies/TSHuth.pdf.

10. Bała, P., Krawczyk, J., Hanc, A., \& Dercz, G. (2010). The Mössbauer spectroscopy and X-ray diffraction studies of phase transformation during tempering in high-carbon tool steel. Solid State Phenom., 163, 200-203. DOI: 10.4028/www.scientific.net/ SSP.163.200.

11. Min, N., Li, W., Li, H., \& Jin, X. (2010). Atom probe and Mössbauer spectroscopy investigations of cementite dissolution in a cold drawn eutectoid steel. $J$. Mater. Sci. Technol., 26(9), 776-782. DOI: 10.1016/ S1005-0302(10)60123-5.

12. Güler, E., \& Akta, H. (2006). Mössbauer studies on an AISI 1137 type steel. Bull. Mat. Sci., 29(3), 303-306. DOI: $10.1007 / \mathrm{BF} 02706500$.

13. Górka, B., Budzynowski, T. W., \& Brzózka, K. (2013). Structure of the superficial region and mechanical properties of nitrided cast steels. Nukleonika, 58(1), 117-121.

14. Simon, G., Vasconcellos, M. A. Z., \& dos Santos, C. A. (1998). Effects of argon irradiation on a plasmanitrided carbon steel. Surf. Coat. Technol., 102, 90-96. DOI: 10.1016/S0257-8972(97)00691-9.

15. Oh, S. J., Cook, D. C., \& Townsend, H. E. (1998). Characterization of iron oxides commonly formed as corrosion products on steel. Hyperfine Interact., 112, 59-65. DOI: 10.1023/A:1011076308501.

16. Brzózka, K., Żurowski, W., \& Górka, B. (2013). Structure of friction products and the surface of tribological system elements. Nukleonika, 58(1), 99-103.

17. Konieczny, R., \& Idczak, R. (2015). Atomic shortrange order in mechanically synthesized iron based Fe-Zn alloys studied by ${ }^{57} \mathrm{Fe}$ Mössbauer spectroscopy. Nukleonika, 60(1), 69-73. DOI: 10.1515/nuka2015-0017.

18. Konieczny, R., Idczak, R., \& Chojcan, J. (2015). Interactions between osmium atoms dissolved in iron observed by the ${ }^{57} \mathrm{Fe}$ Mössbauer spectroscopy. Nukleonika, 60(1), 75-79. DOI: 10.1515/nuka-2015-0016.

19. Szumiata, T., Brzózka, K., Gawroński, M., Górka, B., Javed, A., Morley, N. A., \& Gibbs, M. R. J. (2011). Structural and magnetic ordering in Fe-Ga thin films examined by Mössbauer spectrometry. Acta Phys. Pol. A, 119, 21-23. DOI: 10.12693/APhysPolA.119.21.

20. Herranz, T., Rojas, S., Pérez-Alonso, F. J., Ojeda, M., Terreros, P., \& Fierro, J. L. G. (2006). Genesis of iron carbides and their role in the synthesis of hydrocarbons from synthesis gas. J. Catal., 243, 199-211. DOI: 10.1016/j.jcat.2006.07.012.

21. Bała, P., Krawczyk, J., \& Hanc, A. (2008). The Mössbauer spectroscopy studies of $\varepsilon$ to cementite carbides transformation during isothermal heating from as-quenched state of high carbon tool steel. Acta Phys. Pol. A, 114, 1641-1650. DOI: 10.12693/ APhysPolA.114.1641. 